\title{
Changes in antidepressant use by young people and suicidal behavior after FDA warnings and media coverage: quasi-experimental study
}

\author{
(c) (1) (1) OPEN ACCESS
}

Christine Y Lu instructor ${ }^{1}$, Fang Zhang assistant professor ${ }^{1}$, Matthew D Lakoma analyst ${ }^{1}$, Jeanne M Madden instructor ${ }^{1}$, Donna Rusinak program manager ${ }^{1}$, Robert B Penfold assistant investigator; affiliate assistant professor ${ }^{23}$, Gregory Simon senior invstigator; lead investigator ${ }^{24}$, Brian K Ahmedani assistant research scientist ${ }^{5}$, Gregory Clarke senior investigator ${ }^{6}$, Enid M Hunkeler senior research scientist $^{7}$, Beth Waitzfelder investigator ${ }^{8}$, Ashli Owen-Smith assistant investigator ${ }^{9}$, Marsha A Raebel senior investigator $^{10}$, Rebecca Rossom geriatric psychiatrist ${ }^{11}$, Karen J Coleman research scientist ${ }^{12}$, Laurel A Copeland associate director ${ }^{13}$, Stephen B Soumerai professor ${ }^{1}$

\begin{abstract}
${ }^{1}$ Department of Population Medicine, Harvard Medical School and Harvard Pilgrim Health Care Institute, Boston, MA, USA; ${ }^{2}$ Group Health Research Institute, Seattle, WA, USA; ${ }^{3}$ Department of Health Services Research, University of Washington, Seattle, WA, USA; ${ }^{4}$ Mental Health Research Network; ${ }^{5}$ Center for Health Policy and Health Services Research, Henry Ford Health System, Detroit, MI, USA; ${ }^{6}$ Kaiser Permanente Center for Health Research, Portland, OR, USA; ${ }^{7}$ The Division of Research, Kaiser Permanente Medical Care Program Northern California, Oakland, CA, USA; ${ }^{8}$ Kaiser Permanente Center for Health Research Hawaii, Honolulu, HI, USA; ${ }^{9}$ The Center for Health Research Southeast, Kaiser Permanente Georgia, Atlanta, GA, USA; ${ }^{10}$ Kaiser Permanente Colorado Institute for Health Research, Denver, CO, USA; ${ }^{11}$ HealthPartners Institute for Education and Research, Bloomington, MN, USA; ${ }^{12}$ Kaiser Permanente Southern California, Department of Research and Evaluation, Pasadena, CA, USA; ${ }^{13}$ Center for Applied Health Research, Central Texas Veterans Health Care System jointly with Scott \& White Healthcare, Temple, TX, USA
\end{abstract}

\begin{abstract}
Objective To investigate if the widely publicized warnings in 2003 from the US Food and Drug Administration about a possible increased risk of suicidality with antidepressant use in young people were associated with changes in antidepressant use, suicide attempts, and completed suicides among young people.

Design Quasi-experimental study assessing changes in outcomes after the warnings, controlling for pre-existing trends.

Setting Automated healthcare claims data (2000-10) derived from the virtual data warehouse of 11 health plans in the US Mental Health Research Network.

Participants Study cohorts included adolescents (around 1.1 million), young adults (around 1.4 million), and adults (around 5 million).

Main outcome measures Rates of antidepressant dispensings, psychotropic drug poisonings (a validated proxy for suicide attempts), and completed suicides.
\end{abstract}

Results Trends in antidepressant use and poisonings changed abruptly after the warnings. In the second year after the warnings, relative changes in antidepressant use were $-31.0 \%$ (95\% confidence interval $-33.0 \%$ to $-29.0 \%)$ among adolescents, $-24.3 \%(-25.4 \%$ to $-23.2 \%)$ among young adults, and $-14.5 \%(-16.0 \%$ to $-12.9 \%)$ among adults. These reflected absolute reductions of 696, 1216, and 1621 dispensings per 100000 people among adolescents, young adults, and adults, respectively. Simultaneously, there were significant, relative increases in psychotropic drug poisonings in adolescents $(21.7 \%, 95 \%$ confidence interval $4.9 \%$ to $38.5 \%$ ) and young adults (33.7\%, $26.9 \%$ to $40.4 \%$ ) but not among adults $(5.2 \%,-6.5 \%$ to $16.9 \%)$. These reflected absolute increases of 2 and 4 poisonings per 100000 people among adolescents and young adults, respectively (approximately 77 additional poisonings in our cohort of 2.5 million young people). Completed suicides did not change for any age group.

Conclusions Safety warnings about antidepressants and widespread media coverage decreased antidepressant use, and there were simultaneous increases in suicide attempts among young people. It is essential to monitor and reduce possible unintended consequences of FDA warnings and media reporting. 


\section{Introduction}

Conflicting evidence on the true effects of antidepressants on suicide risk in young people has generated much controversy. ${ }^{1-7}$ Between 2003 and 2004 the US Food and Drug Administration issued several health advisories warning that children and adolescents taking antidepressants were at increased risk of suicidality (suicidal ideation and behavior). In October 2004 the FDA required a boxed warning of this risk to be on the labels of all antidepressant drugs. In May 2007 the FDA extended the warnings to include young adults.

The basis for the decision on the boxed warning has been contentious. ${ }^{89}$ An FDA solicited meta-analysis showed a relative risk for suicidal behavior or ideation of 1.95 (95\% confidence interval 1.28 to 2.98 ) for young people treated with antidepressants compared with those given placebo. ${ }^{4}$ However, the trials included in the meta-analysis were never designed to estimate the risk of suicidality. ${ }^{4}$ Also, the majority of adverse events reported in the meta-analysis involved suicidal ideation, not suicide attempts or completed suicides. ${ }^{49}$ Despite this inconclusive evidence, the FDA advisories and the boxed warning received repeated and widespread media coverage in major newspapers and television networks. ${ }^{10}$ Many news stories used anecdotes and emphasized the risk of antidepressant use by children and adolescents. ${ }^{10}$ Thus, well intended safety warnings became frightening alarms to clinicians, parents, and young people. For example, one New York Times headline stated "FDA links drugs to being suicidal," Washington Post reported "FDA confirms antidepressants raise children's suicide risk." 12

Suicide among young people is a devastating but preventable tragedy. In the United States in 2007, suicide was the third leading cause of death among people aged 15 to $24 .{ }^{13}$ Nearly $8 \%$ of high school students reported attempting suicide in 2011 and $2.4 \%$ made an attempt that required medical attention. ${ }^{14}$ There has been considerable concern that suicidal behavior is a potential adverse outcome of prescription drug use, including antidepressant and anticonvulsant agents. ${ }^{15}$

Treating depression in young people with antidepressants can improve mood. ${ }^{16-18}$ However, the relation between antidepressant use and suicidal behavior is complex, and studies using different methods yield apparently contradictory results. Pre-existing suicidal ideation or behavior may be a precipitant for initiating antidepressant treatment. ${ }^{7}$ While treatment with antidepressants may reduce that pre-existing risk of suicidal ideation, this finding may not hold in young people. ${ }^{18}$ In adolescents and young adults, initiation of antidepressant treatment may precipitate short term increases in suicidal ideation and behavior. ${ }^{419}{ }^{20}$ Given this complexity, warnings about the safety of antidepressant drugs could have unpredictable effects on drug use and suicidal behavior.?

Previous studies of the FDA warnings have found substantial reductions in antidepressant treatment in children and adolescents after the warnings. ${ }^{21-24}$ The reduction even spilled over to adults, who were never a target of the warnings. ${ }^{25}$ The warnings were also associated with declines in depression diagnoses in children and adults. ${ }^{21} 22{ }^{25}$ Studies reported no increase in use of treatment alternatives (for example, psychotherapy, atypical antipsychotics) among young people, ${ }^{21} 22{ }^{24}$ and no increase in the monitoring of patients despite an explicit call for this in the boxed warning. ${ }^{23} 26$

We investigated if the warnings and related media coverage were associated with changes in antidepressant use and suicidal behavior. Our study differs from previous studies in that it provides empirical evidence about changes in suicide attempts and completed suicides using nationwide, long term follow-up after the FDA warnings (2005-10). Because depression is an independent risk factor for suicidality, and appropriate treatment with antidepressants is effective in reducing depressive symptoms, we hypothesized that decreasing rates of overall antidepressant treatment after the warnings would be associated with a net increase in suicide attempts among young people.

\section{Methods}

\section{Health plans and data source}

This study included 11 geographically distributed US healthcare organizations that provide care to a diverse population of 10 million people in 12 states. All organizations are members of the Mental Health Research Network (www.mhresearchnetwork. org), a division of the larger HMO Research Network, an established consortium of 19 research centers affiliated with large not for profit integrated healthcare systems (www. hmoresearchnetwork.org). ${ }^{27}$ Members are enrolled through employer sponsored insurance, individual insurance plans, and capitated Medicare and Medicaid programs. Members served by these systems are generally representative of each system's geographic service area ${ }^{27}$ (see supplementary table A).

Data were obtained from the HMO Research Network Virtual Data Warehouse. ${ }^{27-29}$ A common obstacle to multisite research projects is the variation in automated data systems between sites, making it challenging to generate datasets that can be easily merged across sites. To overcome this, the virtual data warehouse is a series of data standards and automated processes that guide the generation of similarly constructed data tables at each organization. In this federated data structure, protected health information remains at each organization, but common data definitions and formats facilitate sharing of deidentified data for research. The virtual data warehouse includes information on demographics, health plan enrollment, utilization of inpatient and outpatient care, and outpatient pharmacy data. At each site, source data are extracted from the health plan administrative and claims databases and electronic medical records. The virtual data warehouse also includes date (month, year) and information on causes of death, derived from state death registries and internal health plan data. There is generally a lag time of 12-24 months for both reporting of deaths and availability of data; therefore we analyzed data on deaths up to and including 2008. To develop each site's study dataset, standardized programs were written at the lead study site and distributed to participating sites. Each site executed the programs on its virtual data warehouse tables and returned the resulting dataset to the lead site, where site specific study datasets were combined and analyzed. This study was approved by institutional ethics committees at each participating site as well as from state departments of public health when required for the use of information from death certificates.

\section{Study cohorts and outcome measures}

Study cohorts included all adolescents (ages 10-17), young adults (ages 18-29), and adults (ages 30-64). We used these cut-offs because the prevalence of serious suicidal thoughts, planning, and attempts is higher among young adults aged 18-29 than among adults aged 30 and older, based on national data from the US Centers for Disease Control and Prevention. ${ }^{30}$ Adults were not targeted by the warnings and were included as a "control" group. Because previous studies showed that rates of depression diagnosis changed after the warnings ${ }^{21} 2225$ and that outpatient claims are often incomplete for mental health conditions such as depression, ${ }^{31}{ }^{32}$ to avoid introducing selection 
bias, we did not limit our cohorts to those with a coded diagnosis of depression.

To assess changes in antidepressant use after the warnings, we identified a rolling cohort of continuous enrollees. We calculated the quarterly percentage of enrollees who were dispensed an antidepressant. We included all antidepressant agents because the warnings affected the entire therapeutic class.

To examine changes in suicide attempts after the warnings, we used the same denominator population as defined previously. While encounters for suicide attempts can be identified in administrative databases using external cause of injury codes (E-codes), they are known to be incompletely captured in commercial plan databases. ${ }^{33}$ Our preliminary analysis found that E-code completeness varied across study sites, treatment settings, and years. ${ }^{34}$ Therefore, instead of deliberate self harm E-codes, we used poisoning by psychotropic agents (international classification of diseases, ninth revision, clinical modification (ICD-9) code 969), a more reliable proxy for population level suicide attempts. ${ }^{33}$ Poisoning by drugs or toxic substances is the most common method of suicide attempt leading to hospital admission ${ }^{33}$ and emergency room treatments. ${ }^{35}{ }^{36}$ Non-fatal poisoning by psychotropic drugs (predominantly tranquilizers) has a positive predictive value of $79.7 \%$ for suicide attempts (sensitivity was $38.3 \%$ and specificity was $99.3 \%$ ), outperforming other types of injuries or poisonings. ${ }^{33} \mathrm{We}$ calculated the quarterly percentage of enrollees admitted to hospital or treated in emergency rooms for poisoning by a psychotropic drug. In a sensitivity analysis we also calculated the quarterly percentage of enrollees admitted to hospital or treated in emergency rooms for poisoning by any drugs (including non-psychotropic agents such as narcotics and analgesics; ICD-9 codes 960-979).

To examine changes in completed suicides after the warnings, we identified a rolling denominator consisting of people who had enrolled in the health plan for a given quarter or the month immediately before that quarter. We did not require continuous enrollment because health plan membership is terminated by death. We identified deaths with suicide as a cause of death (ICD-10 codes X60-X84, Y87.0) ${ }^{6}$ and calculated the quarterly number of completed suicides per 100000 people.

\section{Study design and statistical analysis}

We used an interrupted times series design, ${ }^{37}$ which can provide powerful evidence of causal effects because it controls for secular trends in study outcomes. The approach measures whether or not a policy (in this study the FDA warnings) causes abrupt changes in the level or the pre-existing trend (slope) of study outcomes. ${ }^{37}$

Time series of population rates are divided into three segments: the pre-warning period (first quarter of 2000 to third quarter of 2003), "phase-in" period (last quarter of 2003 to last quarter of 2004), and post-warning period (first quarter of 2005 to last quarter of 2010). The first segment comprised rates of study outcomes before the FDA warnings. To deal with the possibility of an anticipatory response to the warnings, we considered the last quarter of 2003 to the last quarter of 2004 as a "phase-in" period that spanned the entire period of FDA advisories, the boxed warning, and intense media coverage, and excluded these five data points from the regression models. Excluding these observations also allowed for patients and clinicians to learn about the evidence and consider changing their patterns of antidepressant use. Thus, the approach evaluated the effects of the warnings at "full strength." The final segment comprised rates of study outcomes after the warnings.
We used segmented regression models ${ }^{37}$ to estimate changes at cohort level in our outcome measures from the pre-warnings period to the post-warnings period. A segmented regression model statistically estimates the differences in intercept and slope coefficients between the pre-warning and post-warning periods. We analyzed each age group separately. In statistical models, we adjusted for baseline (control) trends and for seasonal trends. The models included a binary indicator to estimate the immediate level change in outcomes and a term to estimate the trend change after the warnings. While segmented regression models primarily have a linear specification, polynomial and non-linear regression can be used if the data exhibit non-linear patterns. We included a quadratic term for the post-warnings trend in our models because of observed non-linearity. For parsimony, we excluded non-significant $(\mathrm{P} \geq 0.20)$ time series terms in a stepwise fashion; exclusion of the non-significant terms did not change the coefficients on the remaining terms. ${ }^{37} \mathrm{We}$ controlled for all significant autocorrelation terms in the models because observations over time are correlated. In addition, we also provided absolute and relative differences (with $95 \%$ confidence intervals) ${ }^{38}$ in the second year after the warnings (that is, in the last quarter of 2006), which were estimated by comparing the overall changes in outcome attributable to the warnings with counterfactual estimates of what would have happened without the warnings. We conducted all statistical analyses using SAS (version 9.3, SAS Institute, Cary, NC).

\section{Results}

The study cohorts included approximately 1.1 million adolescents, 1.4 million young adults, and 5 million adults per quarter; the key characteristics were stable over time (table $1 \Downarrow$ ). Figures 1 to $3 \Downarrow \Downarrow \Downarrow$ present the 2000-10 time series of antidepressant dispensings and psychotropic drug poisonings with segmented regression results by age group. Estimated changes in levels and trends of time series from segmented regression models are available in the supplementary file (table B). For ease of interpretation, we also present absolute and relative changes to represent the full effect of the widely publicized warnings in the second year after the warnings. Changes in dispensings of selective serotonin reuptake inhibitors and serotonin-norepinephrine reuptake inhibitors are available in the supplementary file (table C).

\section{Effects of the warnings Adolescents}

After the warnings, there was an abrupt decline in the previously upward trend of antidepressant use by adolescents (fig 1). We estimated a relative reduction of $31.0 \%$ in antidepressant use in the second year after the warnings (95\% confidence interval $-33.0 \%$ to $-29.0 \%$; table $2 \Downarrow)$; the absolute change was -0.70 percentage points ( $95 \%$ confidence interval -0.76 to -0.63 ). At the same time as the substantial reduction in antidepressant use, we observed a sharp increase in psychotropic drug poisonings (fig 1). We estimated a significant relative increase of $21.7 \%$ in psychotropic drug poisonings in the second year after the warnings ( $95 \%$ confidence interval 4.9 to 38.5 ); the absolute change was 0.002 percentage points ( 0.0007 to 0.0033$)$. Increases in psychotropic drug poisonings were statistically significant among males (table 2). Our sensitivity analysis also detected a significant relative increase of $13.9 \%$ (10.0\% to $17.8 \%$ ) in poisonings by any drugs among adolescents in the second year after the warnings. 
Completed suicides were rare. Figure 1 presents three point moving averages of quarterly suicide rates over time, adjusting for seasonal trends. We did not observe changes in completed suicides among adolescents; suicide rates ranged from 0.31 to 0.82 per 100000 people per quarter before the warnings, and from 0.28 to 0.68 per 100000 people per quarter after the warnings.

\section{Young adults}

After the warnings, there was an immediate reversal of the upward trend of antidepressant use in young adults (fig 2). We observed a relative reduction of $24.3 \%$ in antidepressant use in the second year after the warnings $(-25.4 \%$ to $-23.2 \%$; table $2)$; the absolute change was -1.22 percentage points $(-1.29$ to $-1.14)$. Simultaneously, there was a noticeable increase in psychotropic drug poisonings (fig 2), with a relative increase of $33.7 \%$ in the second year after the warnings (26.9\% to $40.4 \%)$ and an absolute change of 0.004 percentage points ( 0.0033 to 0.0047). Increases in psychotropic drug poisonings were significant among both sexes (table 2). We observed consistent increases in psychotropic drug poisonings in study sites located in different regions across the country when we combined adolescent and young adult groups (data not shown owing to research ethics and privacy regulations; absolute changes ranged from 0.001 to 0.019 percentage points). Our sensitivity analysis did not detect changes in poisonings by any drugs after the warnings among young adults.

Completed suicide rates appeared to be stable, ranging from 1.25 to 1.76 per 100000 people per quarter before the warnings, and from 1.33 to 1.85 per 100000 people per quarter after the warnings (fig 2). We did not observe discontinuities in completed suicides when we combined the data from adolescents and young adults.

\section{Adults}

After the warnings, antidepressant use decreased suddenly among adults (fig 3). In the second year after the warnings there was a relative reduction of $14.5 \%$ in antidepressant use $(-16.0 \%$ to $-12.9 \%$; table 2$)$; the absolute change was -1.62 percentage points $(-1.83$ to -1.41$)$. There was a statistically insignificant increase in the trend of psychotropic drug poisonings after the warnings (fig 3); we estimated a relative increase of $5.2 \%$ in the second year after the warnings ( -6.5 to 16.9$)$ and an absolute increase of 0.0005 percentage points $(-0.0006$ to 0.0016$)$. Our sensitivity analysis did not find changes in poisonings by any drugs after the warnings among adults. There was no change in completed suicides (fig 3), ranging from 1.76 to 2.06 per 100 000 people per quarter before the warnings, and from 1.86 to 2.27 per 100000 people per quarter after the warnings.

\section{Discussion}

Whether or not a link exists between the use of antidepressant drugs and the emergence of suicidal ideation and behavior in a subset of young people, widely publicized warnings for antidepressants and suicidality could have intended and unintended effects. As hypothesized, we found substantial reductions in antidepressant use, and simultaneous, small increases in psychotropic drug poisonings, a validated measure of suicide attempts, among adolescents and young adults after the FDA warnings targeting youth and widespread media coverage. These results were consistent across our geographically diverse study sites. We did not observe increases in psychotropic drug poisonings among adults, who had smaller reductions in antidepressant use.
Our finding of reduced antidepressant use in young people is consistent with previous studies. ${ }^{21-25}$ Although the FDA extended the warnings to include young adults in May 2007, this single additional communication did not add to the effects of the 2003-04 widely publicized warnings; we did not observe further abrupt changes in antidepressant use among young adults or other age groups. After 2008, the downward trend in antidepressant use among adolescents reversed somewhat; however, utilization remained below 2004 levels. This change may mean that the initial effects of the warnings tapered off or that the May 2007 modification to the FDA messages increased antidepressant use. In the modified message, clinicians and the public were urged to consider the risk of antidepressants alongside the risk of not treating mood disorders. ${ }^{39}$

Our study provides the first evidence that suicide attempts increased rather than decreased after the warnings. Relative increases in non-fatal psychotropic drug poisonings were $21.7 \%$ among adolescents and $33.7 \%$ among young adults in the second year after the warnings. These reflected absolute increases of 77 poisonings in our cohort of 2.5 million young people (22 and 55 additional poisonings among adolescents and young adults, respectively; 2 and 4 additional poisonings per 100000 people). The estimated excess risk of suicide attempt is an underestimate because it is based only on the second year of follow-up and does not include other means of suicide attempts. Since the increase in suicide attempts by poisoning was simultaneous with the significant reductions in antidepressant use, it might be one consequence of under-treatment of mood disorders. This explanation is bolstered by other studies that have found no compensating increases in the use of treatment alternatives among young people. ${ }^{21} 2224$

Our study was the first to examine the effects of the warnings on completed suicides over a long period. In contrast with the increases in suicide attempts, even with large sample sizes we observed no changes in suicides after the warnings. Completed suicides are rare; only one tenth as common as suicide attempts. Nevertheless, our data are consistent with the Centers for Disease Control and Prevention report that showed gradual increases in completed suicides between 1999 and 2010, without sudden discontinuities around the time of the FDA warnings and media reports, among people aged 10-34 years. ${ }^{40}$

\section{Policy implications}

It is possible that the warnings and extensive media attention led to unexpected and unintended population level reductions in treatment for depression and subsequent increases in suicide attempts among young people. FDA advisories and boxed warnings can be crude and inadequate ways to communicate new and sometimes frightening scientific information to the public. Also, the information may be oversimplified and distorted when communicated in the media. ${ }^{10}$ However, we know that the media can influence drug use behavior in positive ways. For example, high profile news reports substantially reduced aspirin use in children and helped eradicate Reye's syndrome. ${ }^{41}$ Greater efforts are needed to improve risk communications to the public and to health professionals. Active surveillance should be considered to allow timely detection and prompt actions to reduce unintended consequences of strong warnings.

\section{Strengths and limitations of this study}

We used an interrupted time series design, which is robust against most threats to internal validity. This study design controls for secular trends in study outcomes (for example, the 
apparent growing epidemic in use of prescription psychotropic drugs outside FDA approved indications) and thereby can attribute abrupt changes to the widely publicized warnings. ${ }^{42}$

Several limitations of this study merit discussion. Firstly, as in other studies using administrative data, we were only able to measure psychotropic drug poisonings that were related to receipt of medical attention, thereby underestimating the true impact of the warnings on suicidality because only about a third of suicide attempts are medically treated. ${ }^{14}$ Secondly, we elected not to use deliberate self harm E-codes because they are incompletely coded across sites in the Mental Health Research Network and in commercial plan databases generally. ${ }^{34}$ Thirdly, we elected not to use a validated algorithm ${ }^{33}$ based on a combination of diagnoses of injury and psychiatric conditions, including depression, to avoid introducing ascertainment bias because previous research found that the rates of depression diagnosis declined after the warnings. ${ }^{21}{ }^{22}{ }^{25}$ Instead, we used psychotropic drug poisonings to estimate changes in suicide attempts after the warnings. While the positive predictive value of psychotropic drug poisonings is lower than the abovementioned algorithm (79.7\% v 87.8\%), it outperforms other injury and poisoning types and has high specificity. ${ }^{33}$ Given that each method only accounts for a small subset of suicide attempts, which are rare, we would not be able to detect any change in population level rates of suicide attempts by other means even with our large sample of 7.5 million. Because psychotropic drug poisonings account for about $38 \%$ of suicide attempts, ${ }^{33}{ }^{36}$ our results underestimate increases in suicide attempts after the warnings. Further, our sample largely included insured populations (commercial plans and public insurers); the findings may not reflect behavior among uninsured patients. Our data sources did not have reliable information on socioeconomic status and race or ethnicity for the early 2000s, thus we did not stratify our analyses by these factors. Finally, our interrupted time series of population rates cannot be used to make inferences about patient level outcomes.

Notwithstanding these limitations, given our study's quasi-experimental design with long term follow-up, we provide rigorous evidence that the FDA warnings and media coverage led to substantial reductions in antidepressant use, which were associated with small increases in suicide attempts by poisonings among young people.

\section{Conclusions}

Undertreated mood disorders can have severe negative consequences. Thus, it is disturbing that after the health advisories, warnings, and media reports about the relation between antidepressant use and suicidality in young people, we found substantial reductions in antidepressant treatment and simultaneous, small but meaningful increases in suicide attempts. It is essential to monitor and reduce possible unintended effects of FDA warnings and media reporting.

We thank all project managers and analysts in participating sites. Contributors: SBS, RBP, CYL, FZ, and GS made substantial contributions to the study conception and design. CYL, SBS, MDL, and DR were responsible for data acquisition. CYL, SBS, MDL, FZ, and JMM were responsible for analysis of data. All authors contributed to interpretation of data. CYL drafted the article and is guarantor. All authors provided critical revisions for important intellectual content and approved the final version.

Funding: This research was supported by a cooperative agreement (U19MH092201; principal investigator, GS) with the US National Institute of Mental Health; SBS was the study principal investigator. The content is solely the responsibility of the authors and does not necessarily represent the official views of the US National Institutes of Health. The sponsor had no role in the design and conduct of the study; analysis, and interpretation of the data; the preparation of the manuscript; and the decision to submit the manuscript for publication. SBS was supported in part by the Health Delivery Systems Center for Diabetes Translational Research (HDS-CDTR) (NIDDK grant 1P30-DK092924).

Competing interests: All authors have completed the ICMJE uniform disclosure form at www.icmje.org/coi_disclosure.pdf (available on request from the corresponding author) and declare that all authors have support from the National Institute of Mental Health for the submitted work. FZ received personal fees from Policy Analysis outside the submitted work. RBP received research funding from Bristol-Meyers Squibb for a study regarding antipsychotic augmentation therapy for major depression in adults only. GS reports grants from Bristol-Myers Squibb outside this work. EH has two pending patents, "Individualized health care management system" (patent application No 11/155 967 publication No US20050283385. Enid Hunkeler, et al. The Permanente Medical Group will own the patent if granted), and "System and method for assisting a care partner in monitoring a patient with chronic disease" (patent application No 11/155 821 publication No US20050283384. Enid Hunkeler, et al. The Permanente Medical Group will own the patent if granted). Other authors declared no financial relationships with any organizations that might have an interest in the submitted work in the previous three years, no other relationships or activities that could appear to have influenced the submitted work.

Ethical approval: This study was approved by the institutional review boards at all participating sites as well as from state departments of public health when required for the use of information from death certificates.

Data sharing: No additional data available. Data were obtained under data users agreements with individual study sites and are not available for sharing.

Transparency: CYL affirms that the manuscript is an honest, accurate, and transparent account of the study being reported; that no important aspects of the study have been omitted; and that any discrepancies from the study as planned (and, if relevant, registered) have been explained.

1 Kaizar EE, Greenhouse JB, Seltman H, Kelleher K. Do antidepressants cause suicidality in children? A Bayesian meta-analysis. Clin Trials 2006:3:73-90; discussion 91-78.

2 Leckman JF, King RA. A developmental perspective on the controversy surrounding the use of SSRIs to treat pediatric depression. Am J Psychiatry 2007;164:1304-6.

3 Simon GE. The antidepressant quandary — considering suicide risk when treating adolescent depression. N Engl J Med 2006;355:2722-3.

4 Hammad TA, Laughren T, Racoosin J. Suicidality in pediatric patients treated with antidepressant drugs. Arch Gen Psychiatry 2006:63:332-9.

5 Olfson M, Marcus SC. A case-control study of antidepressants and attempted suicide during early phase treatment of major depressive episodes. $J$ Clin Psychiatry 2008;69:425-32.

6 Schneeweiss S, Patrick AR, Solomon DH, Mehta J, Dormuth C, Miller M, et al. Variation in the risk of suicide attempts and completed suicides by antidepressant agent in adults: a propensity score-adjusted analysis of 9 years' data. Arch Gen Psychiatry 2010;67:497-506.

7 Simon GE, Savarino J, Operskalski B, Wang PS. Suicide risk during antidepressant treatment. Am J Psychiatry 2006;163:41-7.

8 Baldessarini RJ, Pompili M, Tondo L. Suicidal risk in antidepressant drug trials. Arch Gen Psychiatry 2006;63:246-8.

9 Klein DF. The flawed basis for FDA post-marketing safety decisions: the example of anti-depressants and children. Neuropsychopharmacology 2006;31:689-99.

10 Barry CL, Busch SH. News coverage of FDA warnings on pediatric antidepressant use and suicidality. Pediatrics 2010;125:88-95.

11 Harris G. FDA links drugs to being suicidal. New York Times 2004 Sep 14.

12 Vedantam S. FDA confirms antidepressants raise children's suicide risk. Washington Post 2004 Sep 14

13 National Institute of Mental Health. Suicide in the US: statistics and prevention. 2013. www.nimh.nih.gov/health/publications/suicide-in-the-us-statistics-and-prevention/index. shtml.

14 Eaton DK, Kann L, Kinchen S, Shanklin S, Flint KH, Hawkins J, et al. Youth risk behavior surveillance-United States, 2011. MMWR Surveill Summ 2012;61:1-162.

15 Gibbons RD, Mann JJ. Strategies for quantifying the relationship between medications and suicidal behaviour: what has been learned? Drug Saf 2011;34:375-95.

16 March J, Silva S, Petrycki S, Curry J, Wells K, Fairbank J, et al. Fluoxetine, cognitive-behavioral therapy, and their combination for adolescents with depression: Treatment for Adolescents With Depression Study (TADS) randomized controlled trial. JAMA 2004;292:807-20. 


\section{What is already known on this topic}

The US Food and Drug Administration (FDA) has released safety warnings stating that use of antidepressants may increase the risk of suicidality in youth

The warnings received worldwide publicity and were controversial because the effect of discouraging antidepressant use on suicidal behavior was unknown

Studies have reported reductions in antidepressant use after the warnings, but there are no long term, nationwide studies of subsequent suicidality

\section{What this study adds}

After the FDA warnings, antidepressant use decreased substantially in all age groups and there were simultaneous, small increases in psychotropic drug poisonings, a validated measure of suicide attempts, among adolescents and young adults; these results were consistent across 11 geographically diverse US study sites

Increases in psychotropic drug poisonings were not observed among adults, who were not targeted by the warnings and had smaller reductions in antidepressant use

After the warnings, no change was detected in completed suicide, which is a rare outcome

17 March JS, Silva S, Petrycki S, Curry J, Wells K, Fairbank J, et al. The Treatment for Adolescents With Depression Study (TADS): long-term effectiveness and safety outcomes. Arch Gen Psychiatry 2007;64:1132-43.

18 Gibbons RD, Brown CH, Hur K, Davis J, Mann JJ. Suicidal thoughts and behavior with antidepressant treatment: reanalysis of the randomized placebo-controlled studies of fluoxetine and venlafaxine. Arch Gen Psychiatry 2012;69:580-7.

19 Jick H, Kaye JA, Jick SS. Antidepressants and the risk of suicidal behaviors. JAMA 2004;292:338-43.

20 FDA. Background briefing information. Joint Meeting of the Psychopharmacologic Drugs Advisory Committee and Pediatric Advisory Committee. 2004. www.fda.gov/ohrms/dockets/ ac/04/briefing/2004-4065b1.htm.

21 Libby AM, Brent DA, Morrato EH, Orton HD, Allen R, Valuck RJ. Decline in treatment of pediatric depression after FDA advisory on risk of suicidality with SSRIs. Am J Psychiatry 2007;164:884-91

22 Libby AM, Orton HD, Valuck RJ. Persisting decline in depression treatment after FDA warnings. Arch Gen Psychiatry 2009;66:633-9.

23 Busch SH, Frank RG, Leslie DL, Martin A, Rosenheck RA, Martin EG, et al. Antidepressants and suicide risk: how did specific information in FDA safety warnings affect treatment patterns? Psychiatr Serv 2010;61:11-16

24 Pamer CA, Hammad TA, Wu YT, Kaplan S, Rochester G, Governale L, et al. Changes in US antidepressant and antipsychotic prescription patterns during a period of FDA actions. Pharmacoepidemiol Drug Saf 2010;19:158-74.

25 Valuck RJ, Libby AM, Orton HD, Morrato $E H$, Allen R, Baldessarini RJ. Spillover effects on treatment of adult depression in primary care after FDA advisory on risk of pediatric suicidality with SSRIs. Am J Psychiatry 2007;164:1198-205

26 Morrato EH, Libby AM, Orton HD, Degruy FV 3rd, Brent DA, Allen R, et al. Frequency of provider contact after FDA advisory on risk of pediatric suicidality with SSRIs. Am $J$ Psychiatry 2008;165:42-50.

27 Andrade SE, Raebel MA, Boudreau D, Davis RL, Haffenreffer K, Pawloski PA, et al. Health maintenance organizations/health plans. In: Strom BL, Kimel SE, Hennessy S, eds. Pharmacoepidemiology. 5th ed. Wiley-Blackwell, 2012:163-88.

28 Hornbrook MC, Hart G, Ellis JL, Bachman DJ, Ansell G, Greene SM, et al. Building a virtual cancer research organization. J Natl Cancer Inst Monogr 2005:12-25.

29 Wagner EH, Greene SM, Hart G, Field TS, Fletcher S, Geiger AM, et al. Building a research consortium of large health systems: the Cancer Research Network. J Natl Cancer Inst Monogr 2005:3-11.

30 Crosby AE, Han B, Ortega LAG, Parks SE, Gfoerer J. Suicidal thoughts and behaviors among adults aged $\geq 18$ years-United States, 2008-2009. MMWR Surveill Summ 2011;60(SS-13)

31 Townsend L, Walkup JT, Crystal S, Olfson M. A systematic review of validated methods for identifying depression using administrative data. Pharmacoepidemiol Drug Saf 2012;21(Suppl 1):163-73.
32 Spettell CM, Wall TC, Allison J, Calhoun J, Kobylinski R, Fargason R, et al. Identifying physician-recognized depression from administrative data: consequences for quality measurement. Health Serv Res 2003;38:1081-102.

33 Patrick AR, Miller M, Barber CW, Wang PS, Canning CF, Schneeweiss S. Identification of hospitalizations for intentional self-harm when $\mathrm{E}$-codes are incompletely recorded. Pharmacoepidemiol Drug Saf 2010;19:1263-75.

34 Lu CY, Stewart C, Ahmed AT, Ahmedani BK, Coleman K, Copeland LA, et al. How complete are E-codes in commercial plan claims databases? Pharmacoepidemiol Drug Saf 2014;23:218-20.

35 Spiller HA, Appana S, Brock GN. Epidemiological trends of suicide and attempted suicide by poisoning in the US: 2000-2008. Leg Med (Tokyo) 2010;12:177-83.

36 Ting SA, Sullivan AF, Boudreaux ED, Miller I, Camargo CA Jr. Trends in US emergency department visits for attempted suicide and self-inflicted injury, 1993-2008. Gen Hosp Psychiatry 2012;34:557-65.

37 Wagner AK, Soumerai SB, Zhang F, Ross-Degnan D. Segmented regression analysis of interrupted time series studies in medication use research. J Clin Pharm Ther 2002;27:299-309.

38 Zhang F, Wagner AK, Soumerai SB, Ross-Degnan D. Methods for estimating confidence intervals in interrupted time series analyses of health interventions. J Clin Epidemiol 2009;62:143-8.

39 FDA. Questions and answers on antidepressant use in children, adolescents, and adults: May, 2007. www.fda.gov/Drugs/DrugSafety/InformationbyDrugClass/ucm096321.htm.

40 Centers for Disease Control and Prevention. Suicide among adults aged 35-64 years-United States, 1999-2010. MMWR Morb Mortal Wkly Rep 2013;62:321-5.

41 Soumerai SB, Ross-Degnan D, Kahn JS. Effects of professional and media warnings about the association between aspirin use in children and Reye's syndrome. Milbank $Q$ 1992;70:155-82.

42 Shadish WR, Cook TD, Campbell DT. Experimental and quasi-experimental designs for generalized causal inference. Houghton Mifflin, 2002.

Accepted: 21 May 2014

\section{Cite this as: BMJ 2014;348:g3596}

This is an Open Access article distributed in accordance with the Creative Commons Attribution Non Commercial (CC BY-NC 3.0) license, which permits others to distribute, remix, adapt, build upon this work non-commercially, and license their derivative works on different terms, provided the original work is properly cited and the use is non-commercial. See: http://creativecommons.org/licenses/by-nc/3.0/. 


\section{Tables}

Table 1/ Cohort characteristics. Values are percentages unless stated otherwise

\begin{tabular}{|c|c|c|c|c|c|c|}
\hline \multirow[b]{2}{*}{ Characteristics } & \multicolumn{2}{|c|}{ Pre-warnings } & \multirow{2}{*}{$\begin{array}{c}\text { Phase-in } \\
\text { 2004, 2nd quarter }\end{array}$} & \multicolumn{3}{|c|}{ Post-warnings } \\
\hline & 2001 , last quarter & 2002 , last quarter & & 2006 , last quarter & 2008 , last quarter & 2010 , last quarter \\
\hline Total No & 7179024 & 7303492 & 7167397 & 7399586 & 7473385 & 7618512 \\
\hline \multicolumn{7}{|l|}{ Age (years): } \\
\hline $10-17$ & 14.9 & 15.0 & 15.7 & 14.7 & 14.3 & 14.1 \\
\hline $18-29$ & 19.4 & 19.1 & 18.2 & 18.5 & 18.9 & 18.9 \\
\hline $30-64$ & 65.7 & 66.0 & 66.1 & 66.7 & 66.8 & 67.0 \\
\hline \multicolumn{7}{|l|}{ Aged 10-17: } \\
\hline Total No & 1071473 & 1091651 & 1124142 & 1090431 & 1069152 & 1070522 \\
\hline Female & 49.0 & 49.0 & 49.0 & 49.0 & 49.1 & 49.0 \\
\hline High SES* & 42.8 & 42.6 & 43.1 & 42.8 & 42.6 & $43.0 \dagger$ \\
\hline \multicolumn{7}{|l|}{ Aged 18-29: } \\
\hline Total No & 1388960 & 1391190 & 1306038 & 1370764 & 1410435 & 1442381 \\
\hline Female & 52.8 & 52.8 & 52.9 & 52.5 & 52.6 & 52.9 \\
\hline High SES* & 45.0 & 45.1 & 46.0 & 46.3 & 46.6 & $47.5 \dagger$ \\
\hline \multicolumn{7}{|l|}{ Aged 30-64: } \\
\hline Total No & 4718591 & 4820651 & 4737217 & 4938391 & 4993798 & 5105609 \\
\hline Female & 52.0 & 52.0 & 52.2 & 52.2 & 52.4 & 52.7 \\
\hline High SES* & 49.3 & 49.2 & 49.8 & 49.7 & 49.5 & $50.1 \dagger$ \\
\hline
\end{tabular}

Warnings refer to the widely publicized Food and Drug Administration's advisories and a boxed warning about antidepressant use and the risk of suicidality among young people.

"Based on census data. High SES (socioeconomic status)=members residing in neighborhoods where $>25 \%$ of adults were educated at college. †Calculated based on last quarter of 2009. 
Table 2| Absolute and relative changes in outcomes in second year after warnings compared with expected rates derived from baseline trend

\begin{tabular}{|c|c|c|c|c|c|c|}
\hline \multirow[b]{2}{*}{ Populations } & \multicolumn{3}{|c|}{ All antidepressants } & \multicolumn{3}{|c|}{ Suicide attempts* } \\
\hline & Absolute change & Relative change (\%) & $\begin{array}{l}\text { Absolute change per } \\
100000 \text { people }\end{array}$ & Absolute change & Relative change (\%) & $\begin{array}{l}\text { Absolute change } \\
\text { per } 100000 \text { people }\end{array}$ \\
\hline \multicolumn{7}{|l|}{ Overall: } \\
\hline $\begin{array}{l}\text { Children and } \\
\text { adolescents }\end{array}$ & $\begin{array}{c}-0.70(-0.76 \text { to } \\
-0.63)\end{array}$ & $\begin{array}{c}-30.97(-33.0 \text { to } \\
-28.96)\end{array}$ & $-696(-761$ to -632$)$ & $\begin{array}{c}0.0020(0.0007 \text { to } \\
0.0033)\end{array}$ & 21.70 (4.94 to 38.45$)$ & 2 (0.73 to 3.30$)$ \\
\hline Young adults & $\begin{array}{c}-1.22(-1.29 \text { to } \\
-1.14)\end{array}$ & $\begin{array}{c}-24.29(-25.42 \text { to } \\
-23.16)\end{array}$ & $\begin{array}{c}-1216(-1291 \text { to } \\
-1142)\end{array}$ & $\begin{array}{c}0.0040(0.0033 \text { to } \\
0.0047)\end{array}$ & $\begin{array}{c}33.68(26.93 \text { to } \\
40.43)\end{array}$ & 4 (3.33 to 4.73$)$ \\
\hline Adults & $\begin{array}{c}-1.62(-1.83 \text { to } \\
-1.41) \\
\end{array}$ & $\begin{array}{c}-14.46(-16.04 \text { to } \\
-12.88)\end{array}$ & $\begin{array}{c}-1621(-1827 \text { to } \\
-1414)\end{array}$ & $\begin{array}{c}0.0005(-0.0006 \text { to } \\
0.0016)\end{array}$ & $5.19(-6.51$ to 16.89$)$ & $0.52(-0.60$ to 1.64$)$ \\
\hline \multicolumn{7}{|l|}{ Females: } \\
\hline $\begin{array}{l}\text { Children and } \\
\text { adolescents }\end{array}$ & $\begin{array}{c}-0.89(-0.96 \text { to } \\
-0.82) \\
\end{array}$ & $\begin{array}{c}-34.63(-36.39 \text { to } \\
-32.88)\end{array}$ & $-892(-959$ to -824$)$ & $\begin{array}{c}0.0003(-0.0005 \text { to } \\
0.0010)\end{array}$ & $1.74(-3.41$ to 6.88$)$ & $0.26(-0.50$ to 1.01$)$ \\
\hline Young adults & $\begin{array}{c}-1.75(-1.84 \text { to } \\
-1.65) \\
\end{array}$ & $\begin{array}{c}-25.37(-26.43 \text { to } \\
-24.31)\end{array}$ & $\begin{array}{c}-1749(-1846 \text { to } \\
-1652)\end{array}$ & $\begin{array}{c}0.0051(0.0042 \text { to } \\
0.0059)\end{array}$ & $\begin{array}{c}35.94(29.21 \text { to } \\
42.66)\end{array}$ & 5.05 (4.24 to 5.86$)$ \\
\hline Adults & $\begin{array}{c}-2.35(-2.64 \text { to } \\
-2.07)\end{array}$ & $\begin{array}{c}-15.27(-16.84 \text { to } \\
-13.70)\end{array}$ & $\begin{array}{c}-2352(-2636 \text { to } \\
-2068)\end{array}$ & $\begin{array}{c}0.0010(-0.0008 \text { to } \\
0.0027)\end{array}$ & 7.65 (-6.93 to 22.23 ) & $0.99(-0.77$ to 2.74$)$ \\
\hline \multicolumn{7}{|l|}{ Males: } \\
\hline $\begin{array}{l}\text { Children and } \\
\text { adolescents }\end{array}$ & $\begin{array}{c}-0.51(-0.57 \text { to } \\
-0.44)\end{array}$ & $\begin{array}{c}-26.24(-28.88 \text { to } \\
-23.59)\end{array}$ & $-507(-575$ to -439$)$ & $\begin{array}{c}0.0039(0.0025 \text { to } \\
0.0053)\end{array}$ & $\begin{array}{c}104.30(26.65 \text { to } \\
181.91)\end{array}$ & 3.90 (2.47 to 5.33$)$ \\
\hline Young adults & $\begin{array}{c}-0.60(-0.67 \text { to } \\
-0.52)\end{array}$ & $\begin{array}{c}-20.65(-22.67 \text { to } \\
-18.63)\end{array}$ & $-597(-670$ to -524$)$ & $\begin{array}{c}0.0032(0.0024 \text { to } \\
0.0040)\end{array}$ & $\begin{array}{c}33.84 \text { (24.08 to } \\
43.61)\end{array}$ & 3.18 (2.39 to 3.96$)$ \\
\hline Adults & $\begin{array}{c}-0.84(-0.98 \text { to } \\
-0.69)\end{array}$ & $\begin{array}{c}-12.55(-14.44 \text { to } \\
-10.68)\end{array}$ & $-835(-977$ to -693$)$ & $\begin{array}{c}-0.0005(-0.0014 \text { to } \\
0.0005)\end{array}$ & $\begin{array}{c}-6.07(-17.93 \text { to } \\
5.78)\end{array}$ & $-0.47(-1.44$ to 0.50$)$ \\
\hline
\end{tabular}

Observation period: first quarter of 2000 to last quarter of 2010, with data points from phase-in period (last quarter of 2003 to last quarter of 2004 ) excluded from regression models.

*Identified by poisonings using psychotropic agents (ICD-9 code 969). 


\section{Figures}
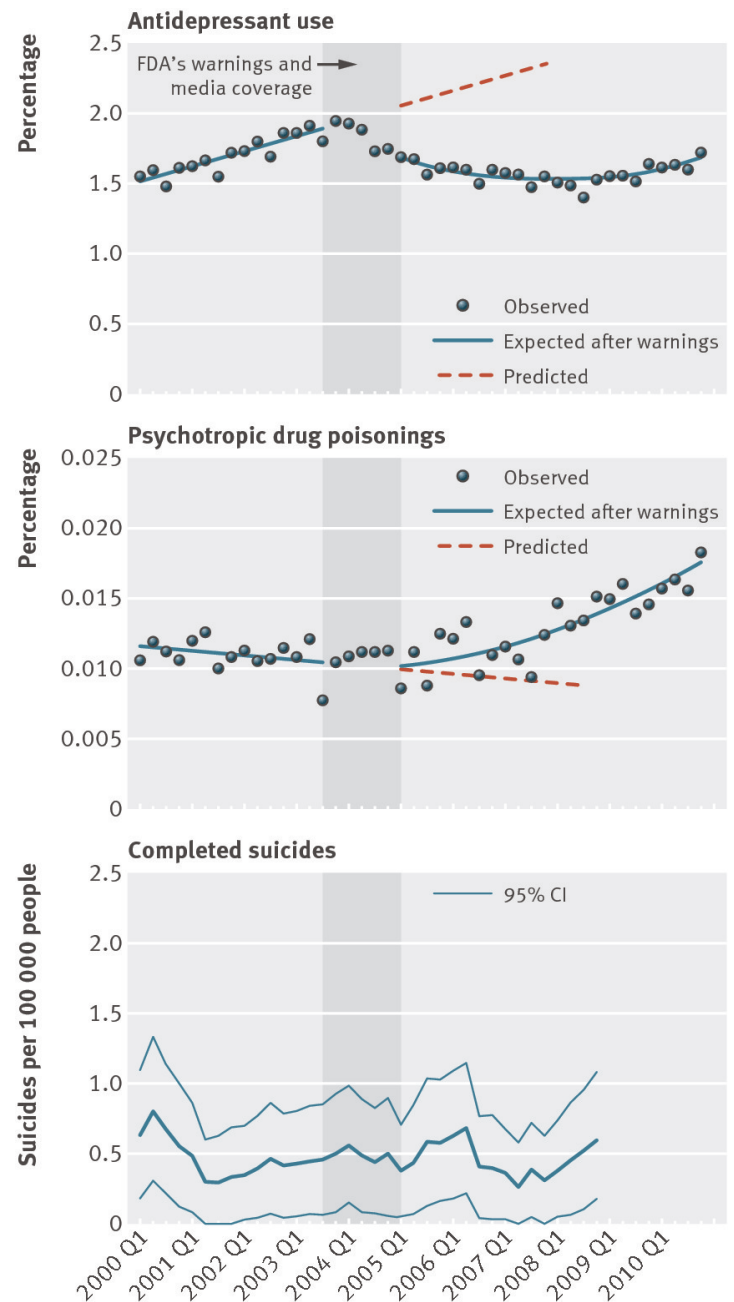

Fig 1 Rates of antidepressant use, psychotropic drug poisonings, and completed suicides per quarter before and after the warnings among adolescents enrolled in 11 health plans in nationwide Mental Health Research Network 

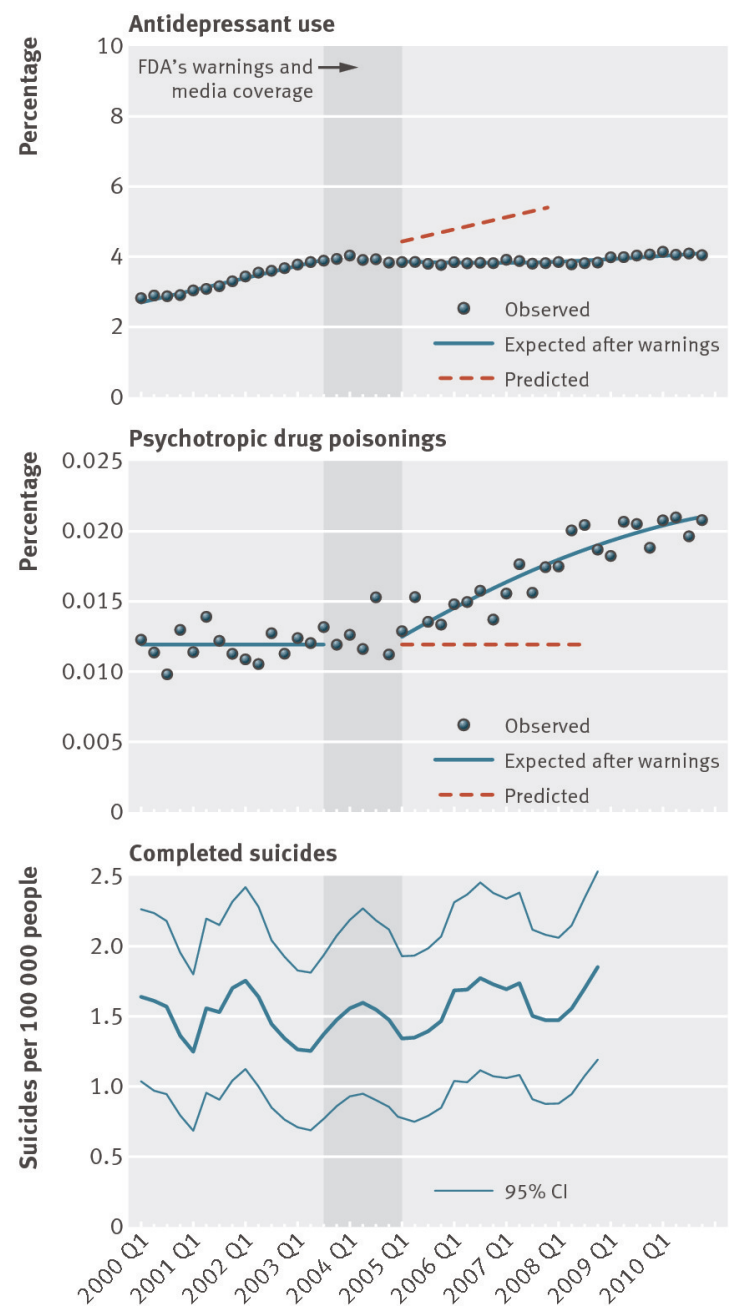

Fig 2 Rates of antidepressant use, psychotropic drug poisonings, and completed suicides per quarter before and after the warnings among young adults enrolled in 11 health plans in nationwide Mental Health Research Network 

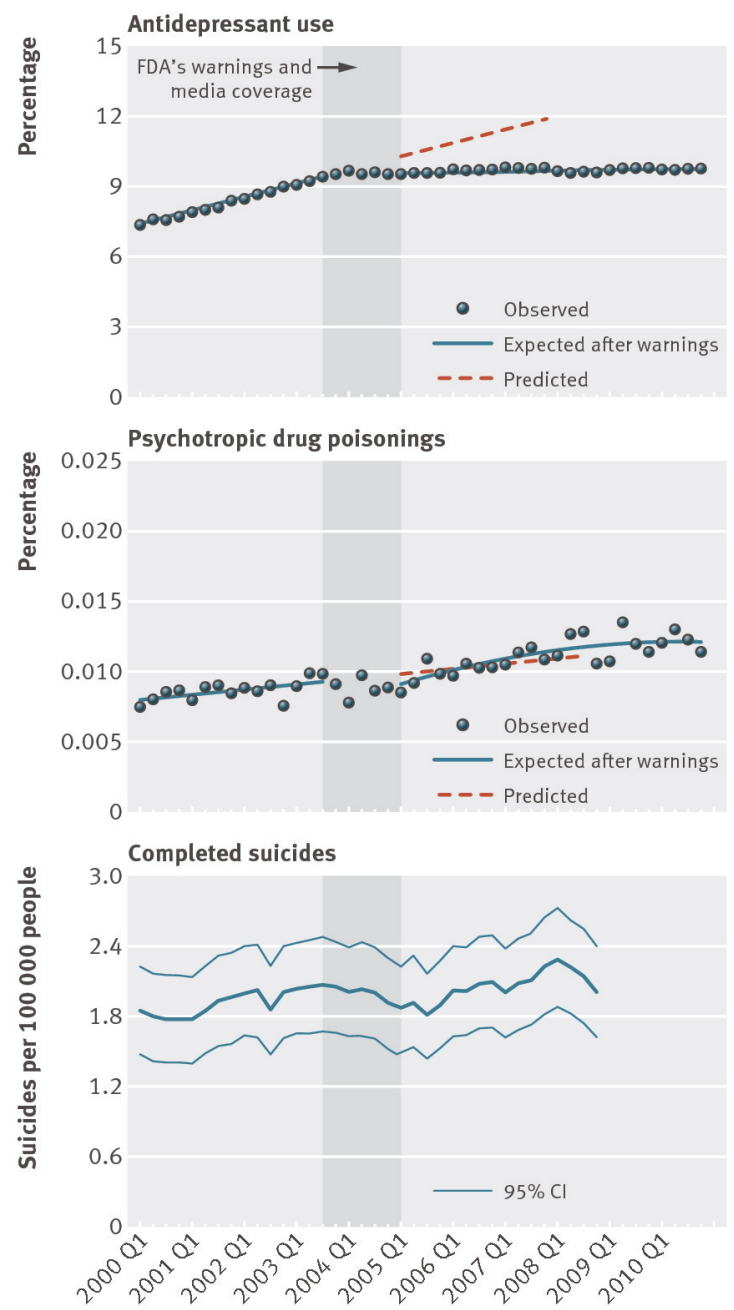

Fig 3 Rates of antidepressant use, psychotropic drug poisonings, and completed suicides per quarter before and after the warnings among adults enrolled in 11 health plans in nationwide Mental Health Research Network 